\title{
Projetos experimentais, projetos integrados e agências experimentais: novas práticas pedagógicas no ensino de comunicação
}

Márcia Perencin Tondato Doutora em Comunicação pela Escola de Comunicações e Artes da Universidade de São Paulo. Professora do Programa de Mestrado em Comunicação e Práticas de Consumo da Escola Superior de Propaganda e Marketing - ESPM-SP.

Pesquisadora do Observatório Iberoamericano de Ficción Televisiva - Obitel.

E-mail: mtondato@espm.br

Resumo: O ensino da comunicação tem exigências oriundas da dinâmica do desenvolvimento tecnológico e intersecção sujeito-objeto de estudo. Aqui apresentamos algumas estratégias de práticas no ensino de comunicação e discussão sobre como estas práticas colaboram para o desenvolvimento do espírito investigativo dos alunos de graduação, incentivando-os à iniciação científica. Em caráter curricular, relacionamos os projetos experimentais e integrados, que promovem a reflexão teórica e a problematização da prática, na medida em que buscam, pelo método científico, soluções inovadoras e criativas para problemas de empresas reais. Em caráter extracurricular, temos as atividades da agência experimental.

Palavras-chave: ensino em comunicação, projetos experimentais, projetos integrados, agências experimentais.
Abstract: Communication teaching demands particular strategies due technological development as well as specific characteristics of the study object, hardly separated from its subject. Here we present some practices in teaching communication and discussion about how they cooperate for the development of investigative skills of graduation students, promoting interest for scientific research. As part of the regular curriculum, we present Experimental and Integrated Projects, that lead students to reflect about theory as they deal with practical situations, having to apply scientific methods to creatively solve problems of real organizations. As extra-curricular activities, we have the practice at the Experimental Agencies.

Keywords: communication teaching, integrated projects, experimental projects, experimental agencies.

O desafio da educação formal ao iniciar o século XXI é fornecer as bases para a construção do conhecimento e formação do cidadão, preparando-o para a prática profissional, tendo como público um jovem bombardeado por 
comunicação \& educação • Ano XV • número 2 • maio/ago 2010

1. O texto faz referência direta à frase "... ० homem é um ser de relações e não só de contatos, não está apenas no mundo, mas com o mundo". In FREIRE, Paulo. Extensão ou comunicação? Rio de Janeiro: Paz e Terra, 1977. p. 39.

2. BAKHTIN, Mikhail. Marxismo e filosofia da linguagem. São Paulo: Hucitec, 1999. p. 71.

3. ISSLER, Bernardo. Objetos de pesquisa e campo comunicacional. In WEBER, Maria Helena; BENTZ, lone; HOHFELDT, Antonio (Org.). Tensões e objetos da pesquisa em comunicação. Porto Alegre: Sulina, 2002. p. 42.

4. LOPES, Maria Immacolata Vassalo. Pesquisa em comunicação. 3. ed. São Paulo: Loyola, 1997. p. 30. informações, acostumado à segmentação, habituado à rapidez, mas também um indivíduo em formação, com receios, dúvidas e ansiedades. Isso exige (re) pensar a função do professor como alguém que reconhece o aluno pela permanente expressão de sua história social e cultural, numa ação constante de comunicação, entendendo que a produção social dos sentidos se dá nas relações sócio-históricas da sociedade e que o indivíduo/aluno está "no mundo e com o mundo"'.

Esse (re)pensar deve romper com o que está sendo feito. O professor não é mais o mestre, transmissor de saberes, mas sim orientador, facilitador, que deve ajudar o indivíduo-aluno a entender uma dinâmica em que não há espaço para errar e consertar, que deve atender às necessidades, antes mesmo que aconteçam.

Na linguagem didático-pedagógica, e até mesmo mercadológica, uma das expressões mais comuns hoje é educação continuada, um processo infinito, sem limitação temporal e espacial. Mais do que nunca nos é exigida a capacidade de reformar, reformatar, rearticular informações, buscando o conhecimento, reforçando a diferença entre informar, em princípio, reproduzir uma informação, e formar, que pressupõe mudança ou adequação de comportamentos. Neste sentido, a melhor tradução da atividade do professor é alguém que deve apresentar as palavras e orientar os aprendentes na busca por um sentido, aproximando-nos o máximo possível de Bakhtin quando diz que:

[...] educar significa propiciar e desencadear processos de auto-organização nos neurônios e nas linguagens das pessoas. [...] Enquanto adquirem novas informações e conhecem novas linguagens, os aprendentes devem poder também, como respeito à versatilidade de seu sistema neuronial, deixar soltos os laços de seus significantes. Quem ensina apenas há de mostrar pistas, insinuar ritmos para a dança das linguagens².

\section{O ENSINAR/APRENDER COMUNICAÇÃO}

Isso no contexto da formação em Comunicação exige trabalhar com um objeto em construção, que influencia e é influenciado pela rapidez das transformações tecnológicas e estruturais, característica apontada por Issler quando diz que "a produção do conhecimento na Comunicação pode ocorrer tanto no interior do seu campo como em campos contíguos e produzir efeitos em todos

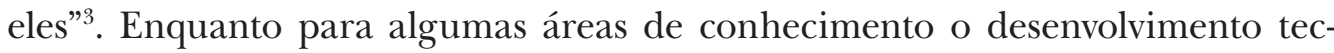
nológico, por exemplo, significa a ampliação da capacidade de manipulação de seus objetos, para a Comunicação, transformações na área tecnológica podem significar, e não raro significam, o surgimento de um novo objeto de estudo. Lopes nos lembra que a diversidade teórica e metodológica das Ciências Sociais é "resultado de uma relação dinâmica entre o estado do conhecimento de uma ciência e o seu contexto social"4.

Inserida no campo das Ciências Sociais, a formação em Comunicação trabalha com a complexidade do ser humano na sua característica racional e 
histórica; o objeto da área é ao mesmo tempo sujeito do estudo; teoria e prática estão juntas, num contexto ideológico ${ }^{5}$. Portanto, formar um comunicador cada vez mais é

[...] capacitar o estudante a perceber o que são e como se dão as ações de comunicação no que se refere ao seu processo, aos conceitos (filosóficos, científicos, jurídicos e outros) em que se fundam, bem como aos instrumentos utilizados e aos conteúdos envolvidos, que tais ações dinamizam ${ }^{6}$.

O desenvolvimento do campo teórico-prático da Comunicação ocorre na interação com os receptores, que ao mesmo tempo que consomem os conteúdos comunicacionais revisam e desenvolvem novos hábitos e formas de leitura do mundo, retroalimentando a emissão. Isto resulta no posicionamento do sujeito comunicador ${ }^{7}$ como formador de opinião, fazendo parte de um sistema tecnológico que "reduziu o diâmetro e a superfície do planeta, reformulando os conceitos tradicionais de tempo e espaço"

Aparte as especificidades do campo, o ensino da comunicação é também problematizado por características estruturais educacionais e mercadológicas, que, no Brasil, se tornam cada vez mais norteadores de um ensino superior de graduação que se afasta dos princípios da universidade, tendo que suprir deficiências do Ensino Médio e, ao mesmo tempo, habilitar os indivíduos para um mercado de trabalho altamente competitivo e dinâmico. Caldas e Schuch, entre outros, alertam para a necessidade da reflexão sobre o impasse entre a formação profissional e a capacitação crítica, com vistas à transformação da sociedade, situação que se agrava em decorrência de um regime professor-horista, com pouco espaço para o fazer universitário, para a realização da pesquisa ${ }^{9}$.

\section{OS CAMINHOS TOMADOS}

Colocado o desafio, soluções são reveladas graças ao empenho e à constância de professores que se disponibilizam à busca de práticas pedagógicas diferenciadas, possibilitando uma formação de graduação consistente com as necessidades acadêmicas, profissionais e sociais.

Discursos sobre educação formal e práticas pedagógicas não raro enfrentam o embate do que seja mais importante: a teoria ou a prática, questão amplamente argumentada por nossos alunos que se ressentem desta ou daquela disciplina por ser muito teórica, sem nada de aplicação prática. Esta dicotomia pode ser resolvida se entendermos que teoria e prática são indissociáveis, na medida em que o ser humano teoriza porque busca encontrar sentidos para os fatos do mundo e que "teorizar é uma forma de agir, unindo a experiência e o sentimento ao pensamento; assim, também, contemplar atentamente fundamenta um ato, traduz uma atitude" ${ }^{\prime 10}$.

Entretanto, no contexto socioeconômico brasileiro, em que a preocupação maior é a colocação no mercado de trabalho, as expectativas dos estudantes são
5. DEMO apud RICHARDSON, Roberto J. Pesquisa social: métodos e técnicas. 3. ed. São Paulo: Atlas, 1999. p. 30.

6. POLISTCHUK, llana; TRINTA, Aluízio Ramos. Teorias da comunicação: o pensamento e a prática da Comunicação Social. 2. reimpr. Rio de Janeiro: Elsevier, 2003. p. 16

7. BACCEGA, Maria Aparecida. Comunicação e linguagem: discursos e ciência. São Paulo: Moderna, 1998.

8. ISSLER, op. cit., p. 40.

9. CALDAS, Graça. Ensino de comunicação no Brasil: panorama e perspectivas. In: PERUZZO, Cicília M. Krohling; SILVA, Robson Bastos da (Org.). Retrato do ensino em comunicação no Brasil: análises e tendências. São Paulo: Intercom; Taubaté, SP: Unitau, 2003; SCHUCH, Hélio Ademar. Adequação do ensino na formação de jornalistas. Revista Brasileira de Ciências da Comunicação, São Paulo: Intercom, v. XXV, n. 1 jan./jun. 2002.

10. POLISTCHUK; TRINTA, op. cit., p. 17-18. 
comunicação \& educação • Ano XV • número 2 • maio/ago 2010

11. BARROS, Laan Mendes de. Para que pesquisar? Comunicação: uma ciência social aplicada. In: LOPES, Maria Immacolata Vassalo de (Org.). Epistemologia da comunicação. São Paulo: Loyola, 2003. p. 233

12. FÍGARO, Roseli. Considerações sobre os resultados da pesquisa de recepção: a construção dos sentidos do trabaIho pelos receptores dos meios de comunicação. Paper apresentado no Congresso da ALAIC - GT Estudios de Recepción, La Plata (ARG), 2004.

13. KUNSCH, Margarida M. Krohling. Propostas pedagógicas para o curso de Relações Públicas. In: PERUZZO, Cicília M Krohling; SILVA, Robson Bastos da (Org.). Retrato do ensino em comunicação no Brasil: análises e tendências. São Paulo: Intercom; Taubaté, SP: Unitau, 2003. p. 50-51.

14. THIOLLENT, Michel. Pesquisa-ação nas organizações. São Paulo: Atlas, 1997. p. 25. focalizadas na obtenção de conhecimentos instrumentais, de aplicação imediata. Mas temos as necessidades impostas pelo campo acadêmico, de construção do conhecimento e desenvolvimento do corpus teórico das habilitações, que inclui tanto a pesquisa teórica quanto a empírica, tradicionalmente delegadas à pós-graduação. Como conciliar estas demandas, em um período de quatro anos, segmentados em disciplinas, cumpridas na maior parte das vezes no curso noturno, deixando o período diurno para atividades remuneradas que viabilizem o custeio dos estudos?

Uma solução é trazer um pouco da sociedade para dentro da sala de aula. Incentivar os alunos a interpretarem a realidade que eles veem lá fora a partir dos conteúdos discutidos aqui dentro (da universidade), ato viabilizado na realização de projetos integrados e experimentais e em agências experimentais. Na prática, atividades que respondem em parte às exigências profissionais e acadêmicas na medida em que têm como princípio o desenvolvimento de problemáticas levantadas a partir de situações reais de comunicação na sociedade; dinâmica que permite que as explicações dos fenômenos ganhem corpo ao serem "sustentadas por um aparato conceitual que já acumula décadas de desenvolvimento e que se renova ao encarar novos fatos e questionamentos"11.

\section{OS PROJETOS EXPERIMENTAIS}

Especificamente, tratamos aqui das necessidades da área de Relações Públicas, cujo fazer tem como espaço o mundo do trabalho, local de destaque na produção de sentidos das trocas comunicacionais, "de grande relevância para a compreensão crítica da sociedade capitalista globalizada e para a apreensão de seus processos de mudança" 12 .

Os projetos experimentais em Relações Públicas existem desde 1984, a partir do reconhecimento da necessidade de um currículo que contribua para a formação profissional para o exercício de funções na atividade de relações públicas, além dos requisitos teóricos mínimos ${ }^{13}$, como por exemplo: o diagnóstico do relacionamento das entidades com seus públicos, com proposições de políticas e estratégias que atendam às necessidades levantadas, por meio da adoção de programas e instrumentos que assegurem a interação das organizações com seus públicos.

Dentre as contribuições da prática do projeto experimental, destacamos a oportunidade dada ao aluno de exercer o trabalho científico tanto mais rico à medida que os dados empíricos são problematizados e desconstruídos, buscando compreender a articulação entre as definições conceituais e as situações reais, entendendo que "o cotejo do real com o ideal não pressupõe uma imagem acabada do que seria o ideal"14. A realização do projeto experimental demanda do aluno, orientado pelos professores, um esforço para a produção de um plano de relacionamento entre a organização-cliente e seus públicos, atendendo às necessidades comunicacionais detectadas. Percebe-se que o cumprimento das exigências resulta no desenvolvimento da maturidade dos estudantes, na 
ampliação das perspectivas de aplicação dos conhecimentos teóricos, finalizando com trabalhos criativos que contemplam as carências do mercado, algumas vezes com propostas diferenciadas, "mudando o conceito de atuação da empresa" e os requisitos da academia.

É notável o desenvolvimento da capacidade de percepção e diagnose dos estudantes. Na observação das lacunas de conhecimento para reconhecimento da situação-problema e levantamentos de informações secundárias para melhor definição de objetivos e construção dos instrumentos, os grupos de alunos se envolvem com os variados públicos da organização, conhecendo em detalhes procedimentos, rotinas, crenças e atitudes. Este exercício os obriga a refletirem sobre a situação das organizações-cliente em um contexto problematizador, essencial para o desenvolvimento de um profissional reflexivo ${ }^{16}$. Isso se evidencia no decorrer do trabalho, quando os alunos muitas vezes têm sua primeira oportunidade de contato com um chão de fábrica, com as exigências e demandas de um empresário, as limitações de um orçamento, a dinâmica de turnos, a atuação de sindicatos e políticas das relações comerciais.

$\mathrm{O}$ atendimento a setores raramente realizados por agências e consultorias no mercado amplia as possibilidades na área de atuação para quem está chegando ao mercado de trabalho, especificamente o comércio varejista, as associações de classe, clínicas médicas, academias e ONGs. Por exemplo, o atendimento ao pequeno comércio varejista exige dos alunos a compreensão de rotinas de trabalho mais orientadas às ações táticas do dia a dia, com públicos segmentados conforme a hora do dia, que necessitam de uma comunicação versátil com fornecedores e de manutenção da motivação dos colaboradores em um clima de trabalho caracterizado pela pressão do consumo imediato e da concorrência acirrada (supermercados e padarias, por exemplo, trabalham praticamente 24 horas por dia, domingos e feriados $)^{17}$.

\section{A AGÊNCIA EXPERIMENTAL}

O projeto experimental, regularmente, acontece no último ano do curso de Relações Públicas, porém, em algumas instituições, os alunos têm a oportunidade de vivenciar antes disso situações práticas na agência experimental, onde "podem compreender a complexidade de cada ação de Relações Públicas e desenvolver as competências necessárias para gerenciá-las eficazmente"18.

As agências experimentais têm como objetivo a ampliação do campo de atuação dos alunos, promovendo espaço de pesquisa e desenvolvimento de serviços específicos, permitindo o conhecimento das ferramentas de trabalho necessárias ao desenvolvimento da atividade profissional por eles escolhida. Entretanto, se isto não for realizado segundo os princípios que salientam que o conhecimento implica o desenvolvimento da capacidade crítica, entendendo que "aprender significa [...] esquecer linhas demarcatórias dos significados já estabelecidos e criar outros significados novos"19, as agências experimentais serão balcão de serviços e os alunos participantes "meros executores de tarefas
15. OLIVEIRA, Maria José da Costa. Projeto experimental em Relações Públicas: teoria e prática na formação profissional. In: PERUZZO, Cicília M. Krohling; SILVA, Robson Bastos da (Org). Retrato do ensino em comunicação no Brasil: análises e tendências. São Paulo: Intercom; Taubaté, SP: Unitau, 2003. p. 208.

16. SCHON, Donald A. Educando o profissional reflexivo. Porto Alegre: Artmed, 2000

17. TONDATO, op. cit., p. 83.

18. MAINARDI, Jocélia. $A$ agência experimental de Relações Públicas e o despertar das competências dos alunos. Revista Estudos de Jornalismo e Relações Públicas, São Bernardo do Campo, SP: Metodista/Faculdade de Jornalismo e Relações Públicas, ano 1, n. 2, p. 59, dez. 2003.

19. ASSMANN, Hugo. Simbiose: imersos em linguagens e campos semânticos. In: Reencantar a educação: rumo à sociedade aprendente. São Paulo: Vozes, 2001. p. 68. 
comunicação \& educação • Ano XV • número 2 • maio/ago 2010

na base da tentativa-erro" ${ }^{20}$. Para tal, as atividades desenvolvidas nas agências devem partir de resoluções tomadas em conjunto entre professores e alunos-estagiários, considerando-se os aspectos estratégicos de cada situação, de forma que os alunos tenham oportunidade de compreender os processos, entendendo sua capacitação como algo construído além de recortes, de saber fazer, buscando formar um indivíduo-aluno que sabe porque sabe.

\section{OS PROJETOS INTEGRADOS}

A realização dos projetos integrados é a oportunidade de organizar os saberes e fazeres vistos nos primeiros semestres, visto que regularmente acontecem no meio do curso. Esta prática cumpre em parte a necessidade do desenvolvimento de projetos inter e transdisciplinares em detrimento de abordagens fragmentárias, que dificultam a formação de uma visão totalizadora de uma realidade complexa ${ }^{21}$. De estrutura semelhante ao projeto experimental, é desenvolvido com menor exigência de abrangência teórica e prática.

$\mathrm{O}$ trabalho integrado possibilita ao aluno uma visão do conjunto das disciplinas ministradas em um mesmo semestre e a sua inserção no programa do curso, abrindo perspectivas e expectativas a serem exploradas nos semestres seguintes. A realização desse trabalho também ajuda na compreensão do conceito do trabalho científico, da imprescindibilidade de sistematização de dados. Os estudantes ficam mais cientes das possibilidades e limitações da atividade, bem como das necessidades e especificidades da formação acadêmica e profissional ${ }^{22}$.

\section{CONCLUSÃO}

As práticas aqui apresentadas para o ensino em comunicação surgem de

20. MAINARDI, op. cit., p. 59.

21. Uma das preocupações expostas no Seminário ECA/FELAFACS sobre o sentido da formação em Comunicação para o século $X X I$, em maio de 2004

22. TONDATO, Márcia Perencin. O projeto experimental de Relações Públicas na Umesp 1999-2004. Revista Estudos de Jornalismo e Relações Públicas, São Bernardo do Campo, SP: Metodista/Faculdade de Jornalismo e Relações Públicas, ano 2, n. 4, p. 79, dez. 2004. ma situação-problema imposta pela precisão de buscar formatos diferenciados para a formação do comunicador, caracterizado como alguém que não só trabalha com comunicação, mas que também tem influência direta na maneira como as pessoas veem o mundo. A hipótese motivadora foi: os formatos tradicionais não dão conta de formar um indivíduo pensante, ético, agente. Como fazer isso, então? Adotando práticas que permitam a interação sala de aula x mundo real, sem relevar o conceitual.

Os projetos experimentais, os integrados e as agências são estratégicas pedagógicas que buscam atender às necessidades de uma era em que o conhecimento é invocado em nome do desenvolvimento humano e da inclusão social, exigindo criatividade, flexibilidade, diversificação dos modos de ensinar e aprender. Estas práticas têm-se mostrado um caminho para a realização de uma educação que consegue bons resultados, entretanto, restam alguns questionamentos não respondidos, visto tratar-se de um processo em desenvolvimento.

Para que o projeto experimental se consolide como um dos marcos na formação do indivíduo-profissional-cidadão, precisamos saber se: 
- permite que o aluno visualize o que se espera dele, como egresso do Ensino Superior?

- na sua forma atual, está atendendo à exigência de capacitar o aluno para ser um transformador da sociedade?

- é possível garantir, ainda que minimamente, que o aluno esteja preparado para exercer a atividade profissional escolhida, contribuindo para o desenvolvimento da área?

No caso do projeto integrado, é importante:

- não transformar sua realização no centro das atividades didático-pedagógicas, possibilitando que alunos sejam carregados pelos grupos ao longo do curso, sedimentando a "cultura do faz de conta" ${ }^{23}$.

- que seja um diferencial de ensino, promovendo a integração das diferentes disciplinas e possibilitando o espaço de uma "prática que evidencie a teoria a ela subjacente" ${ }^{24}$, mas nunca transformado em uma estratégia mercadológica.

A agência experimental, por seu turno, é por excelência o espaço privilegiado da realização de muitos dos ideais pedagógicos, e deve ser entendida, e mantida, como:

- espaço de atividades práticas, realizadas segundo uma dinâmica de intensa interação professor-aluno, permitindo a desmistificação do processo ensino-aprendizagem baseado na transmissão professoral de conhecimento e a recompensa em forma de avaliação classificatória de desempenho;

- espaço de experimentação do novo, de reflexão sobre os erros e compreensão dos acertos, num processo constante de avaliação formativa e somativa.

Importante também lembrar que a agência experimental não é banco de serviço, nem vitrine da instituição.

Relatar experiências, apontando necessidades e deficiências do sistema, é fácil, porém, para que os jovens tenham uma educação superior, desenvolvam competências, capacidade reflexiva, tornando-se indivíduos capazes de promover a transformação, educados para o exercício pleno da cidadania, como expresso nos projetos político-pedagógicos das instituições, é essencial uma tomada de posição diante das práticas hoje existentes, no sentido de aprimorar o que está dando certo e providenciar caminhos para suprir as carências.

Mesmo diante das incertezas de um sistema educacional muitas vezes concentrado no embate público/privado, é importante realizarmos um trabalho de sistematização das práticas positivas, algumas delas aqui apresentadas, procurando, em conjunto, responder aos questionamentos: com o que devemos nos preocupar? Em formar comunicadores? Profissionais? Pesquisadores, acadêmicos? Cidadãos pensantes, éticos, investigativos?

Para responder a esta questão, lembro Sousa Santos, que nos exorta a não abandonar o conhecimento do senso comum, reabilitado pela ciência pós-moderna. Segundo esse pensador, o senso comum, apesar de ser mistificado e mistificador, conservador, "tem uma dimensão utópica que pode ser ampliada através

23. GRECO, Milton. Educação superior para a construção de projetos de vida. São Paulo: Salesiana, 2002. p. 32.

24. POLISTCHUK; TRINTA, op. cit. p. 18. 
comunicação \& educação • Ano XV • número 2 • maio/ago 2010

do diálogo com o conhecimento científico" ${ }^{25}$. Ao abrirmos as portas da sala de aula às experiências externas, não apenas como exemplos de situações a serem resolvidas pela ciência, mas como conhecimento prático e pragmático, que é transparente e por isso mesmo permite "captar a profundidade horizontal das relações conscientes entre pessoas e entre pessoas e coisas" ${ }^{26}$, nos aproximamos do ideal pós-moderno de conhecimento, que "não despreza o conhecimento que produz tecnologia, mas entende que, tal como o conhecimento se deve traduzir em autoconhecimento, o desenvolvimento tecnológico deve traduzir-se em sabedoria de vida" ${ }^{27}$; talvez assim consigamos acompanhar o ritmo frenético da vida moderna, respondendo aos anseios dos jovens que buscam seu espaço no mundo.

\section{REFERÊNCIAS BIBLIOGRÁFICAS}

ASSMANN, Hugo. Simbiose: imersos em linguagens e campos semânticos. In: Reencantar a educação: rumo à sociedade aprendente. São Paulo: Vozes, 2001.

BACCEGA, Maria Aparecida. Comunicação e linguagem: discursos e ciência. São Paulo: Moderna, 1998.

BAKHTIN, Mikhail. Marxismo e filosofia da linguagem. São Paulo: Hucitec, 1999.

BARROS, Laan Mendes de. Para que pesquisar? Comunicação: uma ciência social aplicada. In: LOPES, Maria Immacolata Vassalo de (Org.). Epistemologia da comunicação. São Paulo: Loyola, 2003.

CALDAS, Graça. Ensino de comunicação no Brasil: panorama e perspectivas. In: PERUZZO, Cicília M. Krohling; SILVA, Robson Bastos de (Org.). Retrato do ensino em comunicação no Brasil: análises e tendências. São Paulo: Intercom; Taubaté, SP: Unitau, 2003.

FÍGARO, Roseli. Considerações sobre os resultados da pesquisa de recepção: a construção dos sentidos do trabalho pelos receptores dos meios de comunicação. Paper apresentado no Congresso da ALAIC - GT Estudios de Recepción, La Plata (ARG), 2004.

FREIRE, Paulo. Extensão ou comunicação? Rio de Janeiro: Paz e Terra, 1977.

GRECO, Milton. Educação superior para a construção de projetos de vida. São Paulo: Salesiana, 2002.

ISSLER, Bernardo. Objetos de pesquisa e campo comunicacional. In: WEBER, Maria Helena; BENTZ, Ione; HOHFELDT, Antonio (Org.). Tensões e objetos da

25. SOUSA SANTOS, Boaventura de. Um discurso sobre as ciências. 11. ed. Porto (Portugal): Afrontamento, 1999. p. 56.

26. Ibid.

27. Ibid., p. 57. pesquisa em comunicação. Porto Alegre: Sulina, 2002.

KUNSCH, Margarida M. Krohling. Propostas pedagógicas para o curso de Relações Públicas. In: PERUZZO, Cicília M. Krohling; SILVA, Robson Bastos de (Org.). Retrato do ensino em comunicação no Brasil: análises e tendências. São Paulo: Intercom; Taubaté, SP: Unitau, 2003. 
Projetos experimentais, projetos integrados e agências experimentais - Márcia P. Tondato

LOPES, Maria Immacolata Vassalo. Pesquisa em comunicação. 3. ed. São Paulo: Loyola, 1997.

MAINARDI, Jocélia. A agência experimental de Relações Públicas e o despertar das competências dos alunos. Revista Estudos de Jornalismo e Relações Públicas, São Bernardo do Campo, SP: Metodista/Faculdade de Jornalismo e Relações Públicas, ano 1, n. 2, dez. 2003.

OLIVEIRA, Maria José da Costa. Projeto experimental em Relações Públicas: teoria e prática na formação profissional. In: PERUZZO, Cicília M. Krohling; SILVA, Robson Bastos da (Org.). Retrato do ensino em comunicação no Brasil: análises e tendências. São Paulo: Intercom; Taubaté, SP: Unitau, 2003.

POLISTCHUK, Ilana; TRINTA, Aluízio Ramos. Teorias da comunicação: o pensamento e a prática da Comunicação Social. 2. reimpr. Rio de Janeiro: Elsevier, 2003.

RICHARDSON, Roberto J. Pesquisa social: métodos e técnicas. 3. ed. São Paulo: Atlas, 1999.

SCHON, Donald A. Educando o profissional reflexivo. Porto Alegre: Artmed, 2000.

SCHUCH, Hélio Ademar. Adequação do ensino na formação de jornalistas. Revista Brasileira de Ciências da Comunicação, São Paulo: Intercom, v. XXV, n. 1, jan./jun. 2002.

SOUSA SANTOS, Boaventura de. Um discurso sobre as ciências. 11. ed. Porto (Portugal): Afrontamento, 1999.

THIOLLENT, Michel. Pesquisa-ação nas organizações. São Paulo: Atlas, 1997.

TONDATO, Márcia Perencin. O projeto experimental de Relações Públicas na Umesp - 1999-2004. Revista Estudos de Jornalismo e Relações Públicas, São Bernardo do Campo, SP: Metodista/Faculdade de Jornalismo e Relações Públicas, ano 2, n. 4. dez. 2004. 


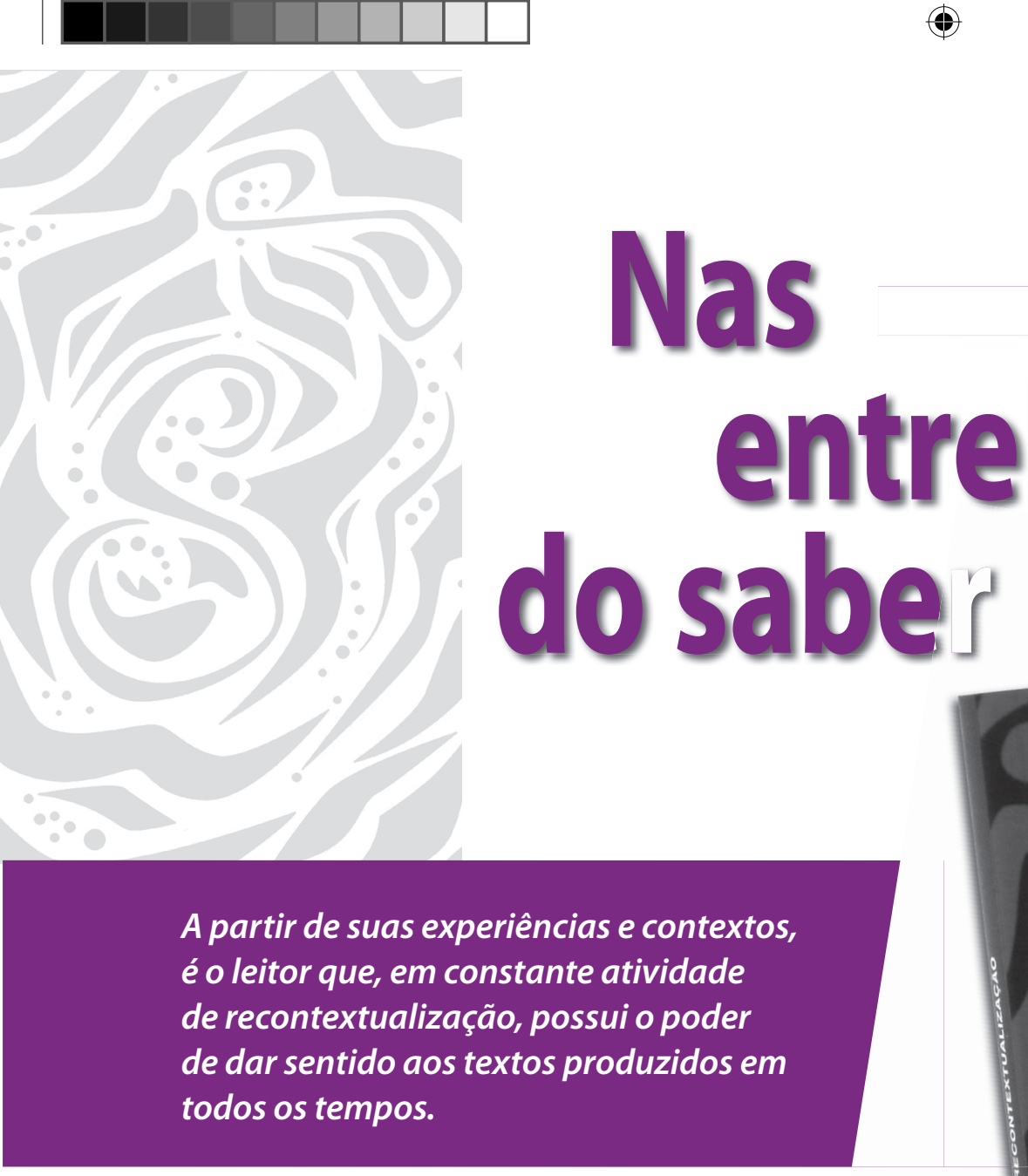

\section{A partir de suas experiências e contextos, é o leitor que, em constante atividade de recontextualização, possui o poder de dar sentido aos textos produzidos em todos os tempos. \\ Leitura e recontextualização O discurso multicultural Bruno Carneiro Lira}

Buscar um significado mais autêntico e satisfatório para $\mathrm{o}$ ato de ler e interpretar textos de todas as culturas e épocas é a finalidade da mais recente obra do filósofo e teólogo padre Bruno Carneiro Lira. Sua expectativa é fazer com que os leitores percebam a importância dos estudos culturais no processo de criação e interpretação textuais.

Dividido em sete capítulos, seu livro vai como que num crescendo, preparando o caminho para uma significativa atividade de leitura. Inicia com o aprofundamento dos estudos culturais, do seu advento aos dias de hoje; mostra, a partir de textos literários, a maneira de construção das identidades e aborda como a leitura e a escrita se constituem um forte instrumento de transformação social. Lira defende o pressuposto de que os discursos são sempre multiculturais, ou seja, não deve haver supremacia de uma cultura sobre outra, e discorre sobre a importância de Bakhtin para os estudos em torno do discurso, sobretudo nos aspectos da dialogicidade e polifonia.

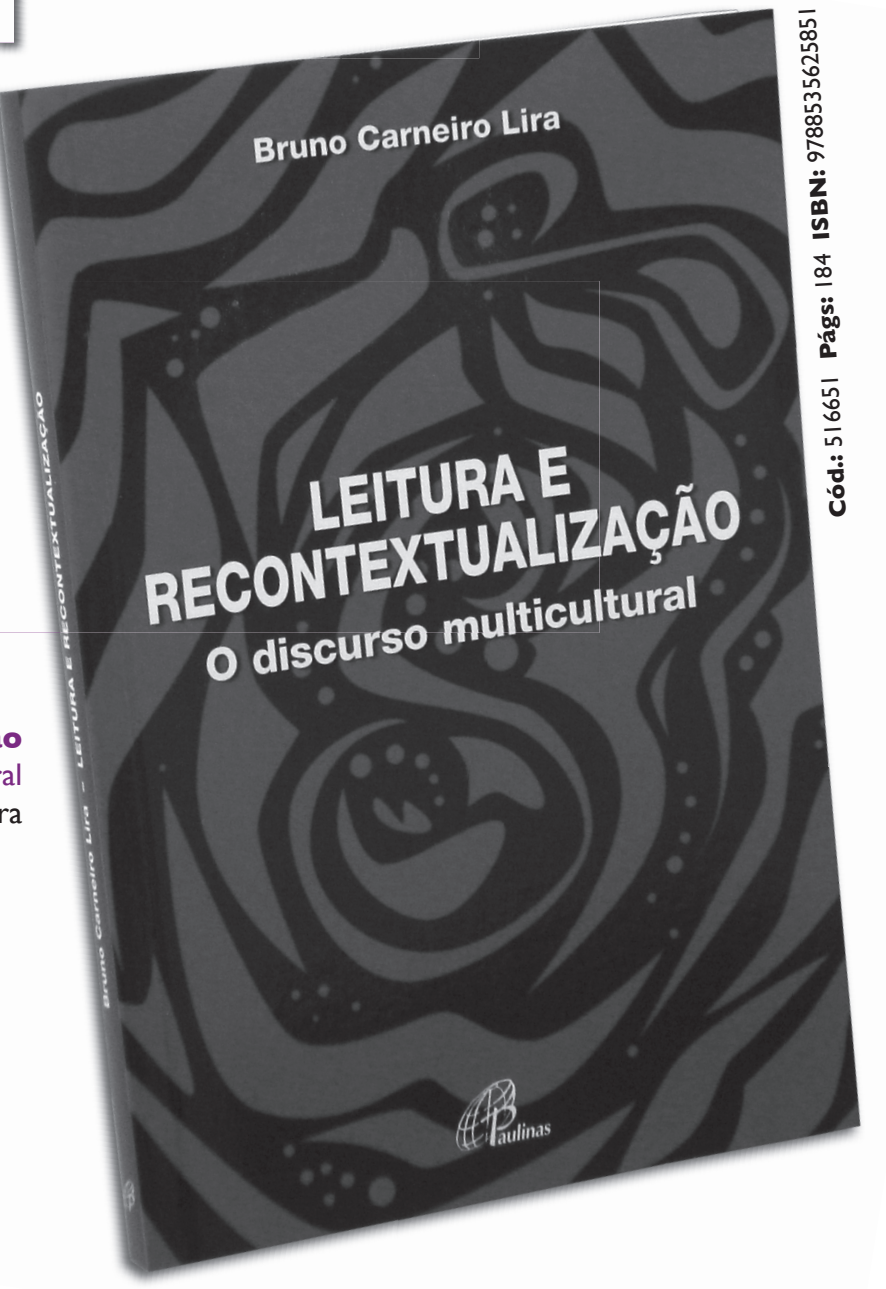

Dedica-se, ainda, à teoria arqueológica discursiva de Michel Foucault, já que este teórico vê o discurso a partir da história, do lado de fora, analisando os textos como um monumento em seu momento de produção. Propõe, assim, que os textos sejam apreciados e estudados a partir da leitura/interpretação, produção e análise linguística; demonstra a presença do implícito e as diferentes interpretações a partir dos diversos contextos; e, finalmente, reafirma a relevância do texto (enquanto rede de significados) como elemento central do ensino e da aprendizagem da língua portuguesa, notadamente da leitura. 